\title{
The Realization of English Vowels by Kuwaiti Speakers
}

\author{
Hanan A. Taqi ${ }^{1}$, Nada A. Algharabali ${ }^{1} \&$ Rahima S. Akbar ${ }^{1}$ \\ ${ }^{1}$ The English Department, College of Basic Education, Ardhiya, Kuwait \\ Correspondence: Hanan A. Taqi, The English Department, College of Basic Education, Ardhiya, Kuwait. E-mail: \\ hanan.taqi@gmail.com
}

$\begin{array}{ll}\text { Received: January 30, } 2018 & \text { Accepted: February 20, } 2018 \text { Online Published: March 17, } 2018 \\ \text { doi:10.5539/ijel.v8n4p1 } & \text { URL: https://doi.org/10.5539/ijel.v8n4p1 }\end{array}$

\begin{abstract}
Learning to speak a language does not necessarily mean learning to realize all the phonemes of that language. When a sound does not exist in a speakers' mother tongue, s/he tends to use a phonotactic; hence, either replacing the sound with another that might sound similar, eliminating the sound, or adding a sound to make it possible to realize. In some cases, the orthography of the target language causes confusion and is considered misleading to non-native speakers. There are only 6 vowels in Arabic phonetics, long and short. Yet, there are 20 phonetic vowel symbols in Received Pronunciation, and 16 in General American. The following study investigates the realization of the English vowels by Kuwaiti speakers, and the effect of orthography on such realizations. 64 male and female Kuwaiti speakers are recorded reading 55 words and 10 sentences. The data obtained was analyzed by Praat (qualitative data), and SPSS (quantitative data). Focus group interviews were also conducted to gain further insight into the topic. It was found that not only do the speakers replace the vowels that do not exist in Arabic, but they also mispronounce vowels that exist in Arabic as they are negatively affected by the English orthography.
\end{abstract}

Keywords: vowels, consonants, Arabic, English, phonotactics, phonology, phonetics

\section{Introduction}

Correct pronunciation is considered an essential part of language fluency. Not only is correct pronunciation important, but it is also very difficult. Lenneberg (1967) posited from a neurological view point, that complete mastery of a second language after puberty is impossible. While many researchers opposed to Lenneberg's theories, to this day, they agree, for different reasons, that a complete command of a language is very difficult. Flege $(1987,1992,1995)$, for example, argues that perception is the main reason for the occurrence of foreign accents. Flege further notes that children learning their L1 would heavily relay on perception as a learning tool, hence by the age of seven, children will be completely tuned to the different L1 phonetic contrasts.

Although L1 has a major effect on learning a new language, sometimes pronunciation errors occur for other reasons. Learning English vowels, for instance, could be problematic as each vowel has several ways of pronunciation (Gimson \& Cruttenden, 1994). In addition, some words are spelled differently, yet they sound the same (e.g., bear and bare). If the learner is not able to fluently pronounce each word by looking at their spelling, then s/he would most likely mispronounce them (O'Connor, 1980).

Research concerned with L2 suggests that pronunciation errors are not random, rather, they are systematic. In some instances, the sounds are not realized correctly because the sound is not familiar to the speaker (Homeidan, 1984). Many researchers (O'Connor, 1980; Carter \& Nunan, 2001; among others) found that speakers who are trying to learn English, substitute English sounds that do not exist in their mother tongue with those which do exist. In addition, the orthography of English is quiet misleading and complicated (O'Connor, 1980).

The current study investigates the ability of Kuwaitis to pronounce the English vowels correctly. The study starts by reviewing the literature associated with language learning and pronunciation. Following that, the study's research questions will be presented. Then, the methodology will be clearly presented, elaborating on the participants, tools and focus. The discussion will later analyze the results, in relation to our review of literature. The study's conclusion will consist of a brief overview of the findings and recommendations for language teachers. 


\section{Literature Review}

A speaker of English as a foreign language who has good pronunciation is much more likely to be understood even if s/he makes grammatical errors (Gilakjani, 2012). Pronunciation is therefore very much a "must" skill for English language learners, and yet for Arabic speakers it is the skill that seems to be acquired with greatest difficulty mainly due to the various differences between the sound systems of Arabic and English. One of the main contributing factors for learner pronunciation difficulties is that Arabic consonants as well as vowel length are phonemic while English's phonetic system is not (McCarthy, 2005).

Several differences lie in consonant sounds in that Arabic, not only has more consonant sounds than English and has no equivalence to a few English consonant sounds, namely the $/ \mathrm{t} f / / \mathrm{p} /$ and $/ \mathrm{v} /$ sounds, but also, Arabic phonotactic rules do not favor consonant clusters meeting in the beginning of a word without being separated by a vowel. To overcome this contrast, learners of English unconsciously insert an anaptyctic vowel to facilitate pronunciation of such words (Al- Saidat, 2010). Also, the Arabic phonetic system has emphatic (as well as non-emphatic) consonants, which typically have a phonological effect on neighboring sounds, especially vowels; a phenomenon that is nonexistent in the English phonetic system (Kopczynski \& Meliani, 1993)

Several other contrastive features lie in the vowel sounds in that English language has 22 distinct vowel sounds, while Arabic has 8. An obvious lack of mapping of Arabic vowel sounds to most English vowel sounds makes it painstakingly challenging for Arabic learners to pronounce English words. The typical pronunciation error we mentioned earlier, vowel insertion by Arab speakers to break English consonant clusters, is one of the commonly researched areas in this field (see for example, Al- Samawi, 2014; Salem, 2014). A study by Jabbari \& Samavarchi (2011), which looked at the syllabification of English consonant clusters in initial position by Persian learners, revealed that hard clusters made of three consonants are simplified by either excluding one of the consonants or adding a vowel before the clusters or in between. Perhaps less researched and thus requiring closer attention is the investigation of comparative acoustic phonetic characteristics of vowel length contrasts between the Arabic and English vocalic systems. It would therefore be of much importance to examine English learners' tendencies to assimilate or substitute vowel sounds from the learner's mother tongue (L1) which are usually unavailable in the second language's (L2) vowel inventory. It is worth noting here that a speaker's phonetic implementation of Arabic vowels varies based on his/her Arabic dialect. It follows that if the vowel system differs slightly according to the learner's dialect, so will the type of interference during the pronunciation of English vowels (Newman \& Verhoeven, 2002; McCarthy, 2005; Alotaibi \& Hussain, 2010). For this reason, cross-language research on vowel durational characteristics and vowel quality should have a wider representation to include the different regional varieties found in Arab learners' phonetic inventory.

Previous studies on cross-language learner's vocalic systems typically focus on the various interferences of the learner's L1 on the perception and pronunciation of L2. Tsukada (2010) for instance, addressed the query of whether native Japanese and non-native Japanese listeners differ in their perceptual categorization of Arabic and English vowel length contrasts. More specifically, a comparison was drawn to establish whether listeners are more sensitive to temporally-defined or spectrally-defined vowel categories. The study concluded with the findings that the two groups of listeners categorized vowels differently based on the phonemic status of vowel length in their L1 phonetic system. Moreover, a similar study with closely related findings was carried out by Zhang et al. (2015) who examined the spectral distance and cross-language vowel systems and whether they affect the perception of English vowel sound contrasts (such as, $/ \mathrm{I} /-/ \mathrm{e} /, / \varepsilon /-/ \mathfrak{x} /, / \mho /-/ \Lambda /$, and $/ \Lambda /-/ \mathrm{p} /$ ) by Chinese EFL learners. The study concludes with predictable findings that the higher the language proficiency is, the more accurate the vowel quality perception (also see Kwon, 2007). While another study conducted by Yiing (2011) on Chinese undergraduate students learning English demonstrated that the English diphthong /ei/ was substituted with the nearest monophthong sound /e/, because of the lack of equivalence in L1. This simplification is mainly due to Mandarin Chinese not having a distinction between long and short vowels.

However, in difference to the studies mentioned above, a study by Kivistio-de Souza \& Carlet (2016) focused on Catalan and Danish EFL learners who tended to overuse vowel duration, as well as being unable to differentiate between vowel distinctions due to the lack of strategic use of perceptual cues (whether temporal or spectral). Also, in a study by Paunovic (2011), Serbian EFL students were observed to compensate vowel length (duration) for appropriate quality differences between vowels in order to achieve maximum intelligibility during speech. Paunovic also shed light on gender distinctions in the realization of certain vowel positions concluding that female participants showed more variation in vowel pronunciation than their male counterparts (also see Wang \& $\mathrm{Wu}, 2001$, who looked at the correlation between vowel duration and the perception of postvocalic consonants). In fact, much of the research in this area has been done with pedagogic implications in mind, especially in terms of common errors and difficulties encountered by Arab learners, which render their speech in English 
unintelligible. One such study by Ali (2013) analyzes the way Sudanese learners produce English vowels. The study suggests that the unawareness of Arab learners with the intricate nature of English vowels coupled with their Arab teachers' misrepresentations of vowel sounds and ineffective methods of language teaching all seem to play a part in learners' pronunciation errors. Ali's findings concluded that learners found English vowels that exist in Sudanese much less confusing than vowels that had no equivalents in Sudanese Arabic, which as a result caused greater L1 interference type errors in L2 pronunciation (see Alimemaji, 2014; Ahmed, 2005). Interestingly, interference of the learner's L1 on L2 is not limited to pronunciation as a skill in its own right since pronunciation inevitably affects other skills, such as reading and writing. It is therefore not unusual for patterns of error in one skill to manifest in another skill. A study by Baloch (2013) observed that spelling mistakes by Arabic students are directly linked to pronunciation misconceptions. She argues that students confuse the consonant "p" with "b" when it appeared before or after vowels, especially the vowel "o" as in "job", which students write as "jop", probably due to the difficulty in pronouncing the $/ \mathrm{p} / \mathrm{phoneme}$ that has no equivalence in Arabic. And yet, much of the findings available in this area do not fully include learners from other parts of the Arab world. Kuwaiti Arabic, for example has a slightly different inventory of vowel variants than its neighboring Arab regions, and therefore, merits instrumental studies that examine vowel length, vowel quality distinctions and instances of phonetic nonequivalence; all of which ultimately create interference errors between L1 and L2. This in turn could provide Kuwaiti linguists with insights into the causes of error production in spoken English by Kuwaiti learners.

\subsection{English Vowels}

It is not the fact that English has five vowel letters (a, e, i, o and u) whereas Arabic has only three (i, a and u), which renders English pronunciation difficult for Arabic learners, but rather the acquisition of twenty-five sound variations of these five English vowels. English has seven pure vowel sounds, known as short monophthongs:

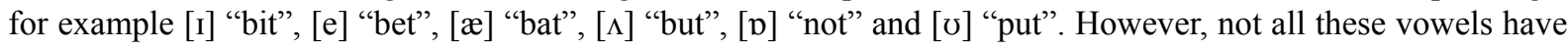
equivalents in longer sounding vowel sounds, since there are only five long monophthongs. Also, the characteristic length of these five monophthongs is dynamic because it is determined by two contextual factors, namely whether or not the vowel is stressed and the influencing sound which follows it. The five long monophthongs are: [i:] as in "squeeze", [3:] "bird", [a:] "palm", [o:] "cord" and [u:] "tool". English also has combined sounding vowels or diphthongs. Diphthongs are "sounds which consist of a movement or glide from one vowel to another" (Roach, 2000, p. 21). There are eight diphthongs in the English language, three of which are centering diphthongs: [гə] as in "cheer", [еә] "care" and [৩ə] "or [ju:] in GA" "cure", and five of which are closing diphthongs: [er], for example "came", [ar] "find", [эr] "oil", [əo] "or [ov] in GA" "home" and [av] "how". Finally, English also has five triphthongs, which are sounds that "glide from one vowel to another and then to a third, all produced rapidly and without interruption" and all ending with [ə], a schwa (Roach, 2000, p. 24). All five triphthongs are: [еюə] as in "player", [агə] "five", [эә] "lawyer", [әјә] "grower" and [aјə] "towel".

\subsection{Arabic Vowels}

The Arabic vocalic system is very straightforward. Modern Standard Arabic has six pure vowels or monophthongs, three of which are long vowels, and these have three direct corresponding letters in the Arabic orthography. The other three vowels are short and are represented by diacritics. Some Arabic dialects also have diphthongs, but unlike the varied English vocalic system, these diphthongs are only two: [au], for example nawm, meaning "sleep" and [er], as in bayt meaning "house". The three long vowel sounds in Modern Standard Arabic are: [i:] as in fee, meaning "in", [u:] noon, meaning "the letter N" and [a:] mal, meaning "money". The three short vowels sounds are: [i], for example min meaning "from", [a] sced, meaning "dam", and [u] hठm, meaning "they".

The difficulty for the Arabic learner does not only lie in the fact that the English vowel sounds by far outnumber the Arabic ones, but also in the arduous task of reading their orthographic representations in written words. Beside the many idiosyncrasies of its spelling system, English (unlike Arabic) is characterized by its spelling and pronunciation not corresponding to one another, as mentioned earlier. An Arabic learner trying to acquire English has to, therefore, struggle with both correctly pronouncing the various English vowel sounds, many of which have no equivalent representations in Arabic, as well as reading the highly variant and tricky vowel representations in the English orthography.

\subsection{Factors that Affect Pronunciation}

Many factors may hinder the learning of pronunciation of the L2. Brown (2000) stated that second language learning difficulties are usually caused by interference of L1, particularly during adulthood. Carter \& Nunan (2001) agreed adding that the most prominent error made by non-native speakers are evidences of L1 transfer. 
The L1 habits of speaking might be different in perception, use of organs and suprasegmental features. Differences found in phonemes, intonation, and tone affect the way people listen to and thus speak a foreign language.

Another problem that might obstruct learning English pronunciation efficiently is L1. This is caused by the fact that the English vowel system might be more complicated than what the speakers have in their L1, which could drive the speakers towards an L1 strategy. In this case, the L2 speaker would intentionally use a vowel from L1 to compensate for the lack of their knowledge of the L2 vowel structure. The L2 strategy is caused by what Gimson \& Cruttenden (1994) called "qualitative opposition". They believed that the difficulty in learning English is caused by the learners' creation of generalization rules. In this case, the learner would realize vowels as s/he overgeneralizes the rules of English spelling. For example, while -o- in "come" and -oo- in "blood" should all sound like $[\Lambda]$, yet "home" does not use the same vowel, neither does "food". The speakers might replace them all with a /u:/ or / $\mathrm{o}: /$. This L2 strategy is caused by the learners' previous knowledge of vowels, as well as the convenience of associating each English vowel with a sound, regardless of irregularities in the English orthography. Therefore, the inconsistency of the pronunciation of English vowels may lead L2 learners to mispronounce words.

In addition to the inconsistency of the pronunciation of vowels, the English spelling system contains many loan words that are uniquely spelled, and many words with silent consonants (Yule, 2001). In Arabic, every vowel and consonant counts. Hence, it is not necessary to know the words or their meanings; letter by letter realizations would provide the correct pronunciation. Therefore, when an L1 speaker of Arabic attempts to learn English, $\mathrm{s} /$ he would read words letter by letter, which most of the time would result in incorrect pronunciation.

This study attempts to look at the main causes of the inability to learn good English pronunciation amongst Kuwaiti learners of English through the investigation of answers to the following research questions,

\section{Research questions:}

How do Kuwaiti speakers realize the English vowels?

1) What English vowels are found most difficult for Kuwaiti speakers?

2) What relationship is there between the pronunciation difficulties of English vowel sounds and the speakers' L1?

3) What relationship is there between the pronunciation difficulties of English vowel sounds and the English orthography?

\section{Methodology}

The study was conducted in 2015 and 2016. First, the study was piloted with a list of 60 words with the forms $\mathrm{CvC}, \mathrm{CvCC}, \mathrm{CCvC}$ and $\mathrm{CCvCC}$. All forms contained a vowel (monophthongs or diphthongs) in medial position. The words in the pilot study consisted 15 vowels, all General American (GA) vowels excluding the schwa. 5 Kuwaiti male and female speakers participated in the pilot study, recording their readings of the list of words on an Edirol-09 digital recorder. From the pilot study, it was found that some vowels rarely undergo any change, while 5 vowels -3 monophthongs and 2 diphthongs - change significantly when realized by Kuwaiti speakers.

Based on the results obtained from the pilot study, the list of words was reformed into a list of 55 words, and 10 sentences were added including the vowels under investigation. In order to collect as much data as possible, the researcher used the snowball (chain) sampling technique, defined by Atkinson \& Flint (2001) as "a technique for gathering research subjects through the identification of an initial subject, who is used to provide the names of other actors."

Participants of the study were male and female Kuwaitis, aged 18-35. Some were students at the time of conducting the study, while the others were working in the public and private sectors. The most important independent variable that all the speakers have in common was that the participants have all studied in public schools in Kuwait. In this case, they would all have about the same access to the English language. Private school graduates were excluded as this would mean very early exposure to language, which might affect the perception and pronunciation according to O'Connor 1980. In the end, participants with clear recordings were 64. 
Table 1. Age and gender of participants

\begin{tabular}{llll}
\hline Gender/Age & $18-21$ & $22-30$ & $30-35$ \\
\hline female & 27 & 7 & 2 \\
male & 22 & 4 & 2 \\
\hline
\end{tabular}

The data was analyzed by measuring average formant frequencies (F1 and F2) through the use of Praat to compare the results with the average formant frequencies of GA adapted from Delattre (1964). The formant frequencies of a vowel is measured both by formants (F1 and F2) and length. The formants are measured as the first formant reflects whether the vowel is open or close, while the second formant reflects back and front vowels. Results attained were based on a comparison of formants in GA.

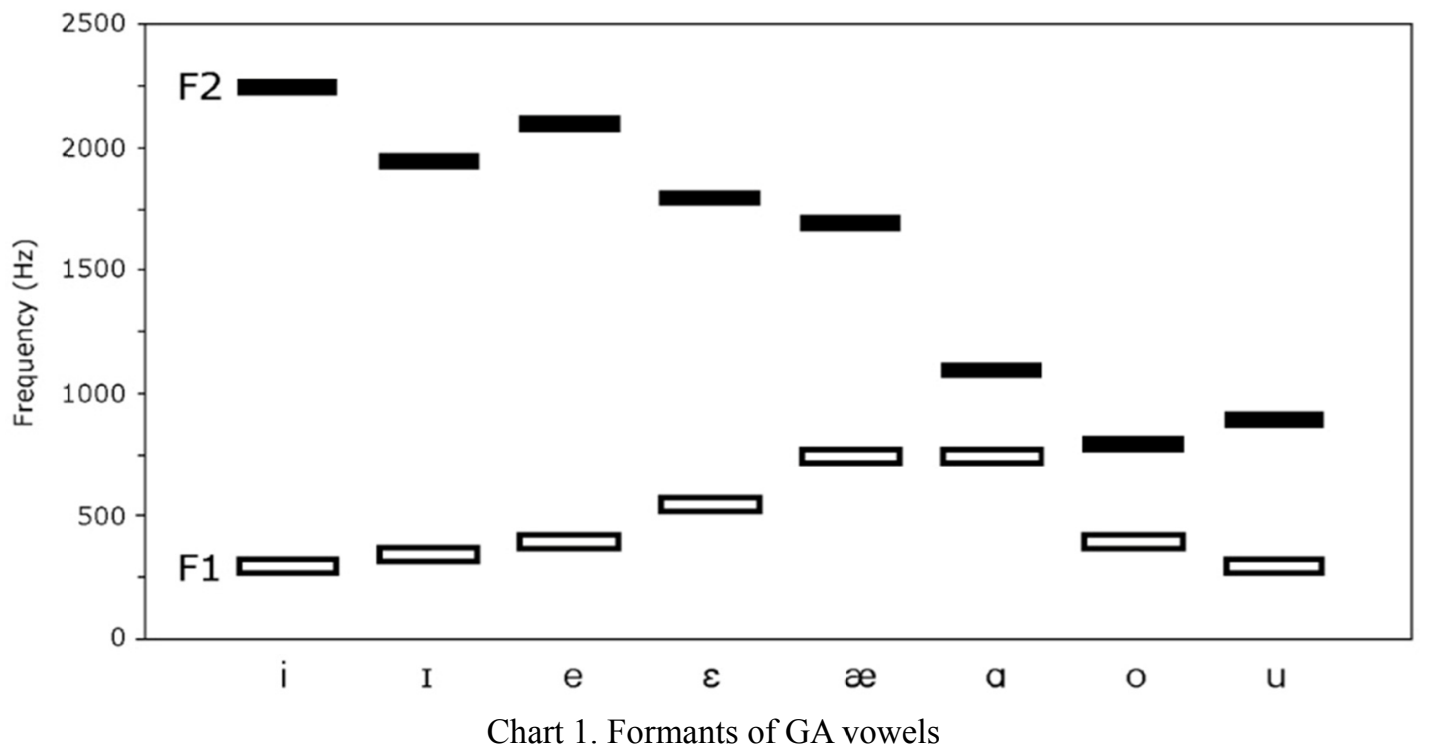

The data related to speakers, their age and gender, and correct realizations were analyzed in SPSS. In the analysis, the frequency, mean, standard deviation of the correct vowel use was measured. In addition, the correlation of age and gender with the realizations are analyzed. The second type of data analyzed F1 and F2 of each word, obtaining the average of each sound's formants to allow for an easy comparison to GA.

In addition to the quantitative data, focus group interviews were conducted to gain qualitative insightful data associated to vowel production in the speech of Kuwaitis. The interview explored the reasons for which certain words were "easier" to read than others. Participants were provided with three lists of words with a common vowel sound in each list (including /eI/, /ov/ and $/ \Lambda /$ ), and were asked to choose the easiest in their opinion, and inform the group of the reason behind that choice. The participants were later given a list with words containing /i:/, in order to decide if they believed one list was easier than the others. The step was taken to identify the techniques Kuwaitis apply while reading. The informants were asked about their favorite reading technique as well. This was followed by listening to a native speaker reading a few words from the lists provided earlier to verify whether the participants can hear the difference in pronunciation. Informants with affirmative response to the last question were further required to provide an explanation.

\section{Results}

The results will be presented according to the vowels investigated. There were 5 vowels under investigation in


[eI] and the monophthong [i:] do; this gives these two sounds a different weight.

Realizations of the diphthongs [er] and [ov] seemed to be the most challenging to Kuwaiti speakers. The percentage for the correct realization of [eI] was $26.3 \%$, reflecting a low mean for female speakers $(\mathrm{m}=30.8)$ and an even lower mean for the male speakers $(\mathrm{m}=20.3)$. However, gender was not found to be a significant factor, while age was in a one-way ANOVA by age as an independent factor, $\mathrm{f} \leq 0.01$ (where significance is measured at $\mathrm{f} \leq 0.05)$. 
The statistics show that while the youngest group of participants realized the vowel [eI] correctly $28.2 \%$ of the time, the eldest group realized it correct the least (12.5\%). The standard deviation for the youngest group was 18.10, and 9.75 for the eldest group. The significance reflects the fact that the younger group has more ability to realize the sounds of English correctly. It is at this point important to identify the sound found in place of [er] in words like "date" and "steak".

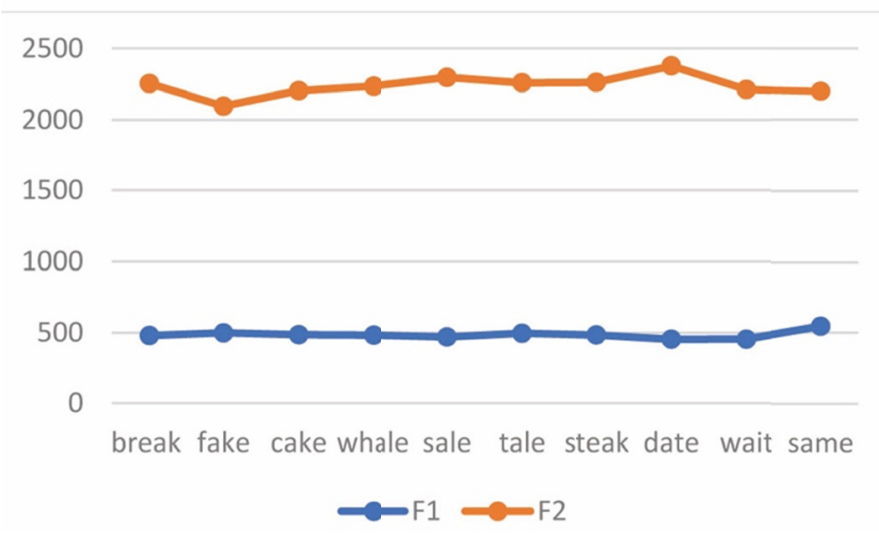

Chart 2. Formants for words with native [eI] sound

As Chart 2 shows, the formants of the vowel are similar to [e] in the GA Chart.

The average F1was found to be $490.67 \mathrm{~Hz}$, and the average F2 was found to be $2281.30 \mathrm{~Hz}$. These measurements correspond with the GA [e] sound as shown in Chart 1 above. The average vowel length was $0.141 \mathrm{~ms}$, which is fairly short for a diphthong. No relationship between the orthography of the words and the pronunciation could be detected as the spellings included three vowel sets $(\mathrm{CaCe}, \mathrm{CCeaC}$ and $\mathrm{CaiC})$. Most words with a native [er] were produced with similar formants and length to [e]. Strangely, the diphthong [er] is commonly used in Arabic, yet the Kuwaiti speakers tended to minimize its use in English.

The second diphthong investigated in this study was [ov]. This sound was found to be very problematic to the Kuwaiti speakers. The [or] sound does not exist in Arabic, and thus might be the reason for the misconception. Although the female participants could realize the vowel $7.33 \%$ more correctly than the male speakers, this difference was not significant. On the other hand, the difference between the age groups realizations was highly significant $(\mathrm{f}=0.046$ ). The significance was found due, yet again, to the fact that only $10 \%$ of the realizations was correct in the older group, as opposed to $24.4 \%$ in the youngest group, and $15.55 \%$ in the middle age group.

Table 2. Gender and age significance in the realization of [ov]

\begin{tabular}{llllll}
\hline Gender & & df & Mean Square & F & Sig. \\
\hline [eI] (gender) & Between Groups & 2 & 541.332 & 1.904 & .158 \\
& Within Groups & 62 & 284.374 & & \\
& Total & 64 & & & \\
{$[$ ov] (gender) } & Between Groups & 2 & 736.867 & 2.837 & .066 \\
& Within Groups & 62 & 259.754 & & \\
& Total & 64 & & & \\
{$[\mathrm{er}]$ (age) } & Between Groups & 1 & 1741.742 & 6.465 & .013 \\
& Within Groups & 63 & 269.398 & & \\
& Total & 64 & & & \\
{$[$ oov] (age) } & Between Groups & 1 & 1088.114 & & \\
& Within Groups & 63 & 261.752 & & \\
& Total & 64 & & & \\
\hline
\end{tabular}

The diphthong [ov] was realized in most instances as [0], a back open-mid vowel which is typically known for F1 approximately $560 \mathrm{~Hz}$ and F2 $820 \mathrm{~Hz}$. An example of this realization would be the word "know" [nov], mostly realized as $/ \mathrm{no} /$. This is evident from the measurement of formants, where the average of $\mathrm{F} 1$ was $531.9 \mathrm{~Hz}$ and $\mathrm{F} 2$ $972.67 \mathrm{~Hz}$, and a vowel length of $0.093 \mathrm{~ms}$ which is very short for a diphthong. 
The first monophthong and third vowel to be investigated is [ช]. Kuwaiti speakers participating in this study mostly realized this vowel as $/ \mathrm{u}: /(46.1 \%$ of the time). As seen previously, the older group found the greatest difficulty pronouncing words like "book" [bok] and "took" [tok]. The realization sounded closer to /bu:k/ and tuk:/ consecutively. In a one-way ANOVA by age, significance was $\mathrm{f}=0.02$, reflecting the significant difference between the young group and the two other age groups, since the youngest group was more correct $9 \%$ of the time. Significance was also found in gender $(\mathrm{f} \leq 0.01)$, as the female speakers realized the $[\mho]$ vowel correctly significantly more than the male speakers $(52.1 \%$ and $38.2 \%$ successively).

The average measurement of vowel length was $0.93 \mathrm{~ms}$, and formants at F1 $439.21 \mathrm{~Hz}$ and F2 $1401.2 \mathrm{~Hz}$. The formants and length strongly reflect a long vowel ([v]is short) that closely resembles [u:] in Chart 1 above. Further investigation of the vowel showed that orthography was the main reason [v] was realized as [u:]. It was evident that most appearances of $\mathrm{CooC}$ would be realized as [u:], for example "cook" [kok] would be realized as /ku:k/. On the other hand, a word spelled $\mathrm{CuC}$ or $\mathrm{CuCC}$ would usually be realized with [ $\mathrm{\sigma}]$ by most participants. A good example of that would be the in words like "put" [pot] and "bush" [bof].

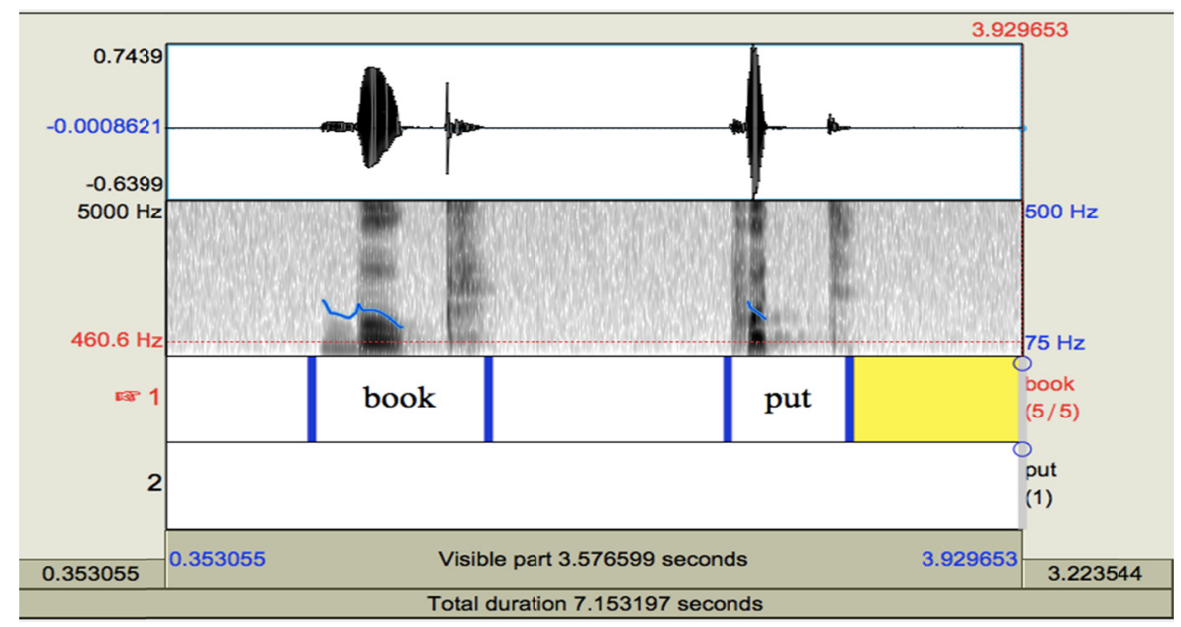

Figure 1. The realization of the words "book" and "put"

As can be seen in Figure 1, the vowels in both words are realized differently.

When analyzing the data for the realization of [i:] and [I], the association between orthography and incorrect realization was detected. For instance, a word like "been" [bin] would almost always be realized as /bi:n/, as the participants seem to feel that any occurrence of $\mathrm{CeeC}$ would mean $/ \mathrm{Ci}: \mathrm{C} /$, as it is normally realized in words like "feel". Moreover, a word like "kiwi" was realized by $32 \%$ of the participants as /kewi:/, while "ship" was realized as $/ \mathrm{i}: \mathrm{p} / 44.6 \%$ of the time. In addition, many participants seemed to assume that $\mathrm{CeaC}$ would be realized as $/ \mathrm{Ci}: \mathrm{C} /$ such as the case in words like "leave" and "meat". Hence, realizations of "pear" and "bear" were mostly /pi:r/ and /bi:r/ consecutively, reflecting the effect of misleading orthography on the non-native speakers. Age and gender did not show to be significant in the realization of [i:] and [I], and the mean of correct realization was 68.15 .

The fifth and final vowel under investigation was the back open-mid [ $\Lambda$ ], with typical F1 680Hz and F2 1310Hz. The words investigated contained two types of English vowels "ou" and "u". In words with "ou" such as "double" [d $\Lambda$ bəl] and "trouble" [tr $\Delta$ bəl], $65.3 \%$ of the participants realized the words as /dæbəl/ and /træbəl/. Yet, in a word like "but", the realization of the vowel was correct. Strangely, the words "touch" and "cousin" were almost always correctly realized.

High significance was found in a one-way ANOVA by age, were $f \leq 0.01$. This significance was due to the oldest group's low mean of correct realization of $[\Lambda]$ in comparison with the youngest and middle groups $(\mathrm{m}=52, \mathrm{~m}=69$, $\mathrm{m}=73$ successively). The average length of the realization of $[\Lambda]$ was calculated according to orthography (words with -ou- and -u-). The average length for words with -ou- was $0.183 \mathrm{~ms}$ with formants measuring at F1 $617.78 \mathrm{~Hz}$ and F2 $1865.67 \mathrm{~Hz}$. The length and formants represent closely those of the [æ] sound. On the other hand, the average length and formants measurements of words with -u- correctly realized with $[\Lambda]$ was $0.078 \mathrm{~ms}$, and F1 $653.9 \mathrm{~Hz}$ and F2 $1292.3 \mathrm{~Hz}$. The difference between the two formant measurements reflects the effect of 
orthography on non-native speakers' realization of sounds.



Figure 2. The realization of "double" and "but"

As can be seen from Figure 2, the orthography affects the realization of words.

Although in terms of gender, female speakers always gained higher in the percentage of correct realizations, significance was only found in the realization of $[\mho]$. Age, however, played a major role as a significant independent variable, where four out of five vowels investigated were significantly realized less correctly by the older age group. The correct realization percentage increased as the age group decreased.

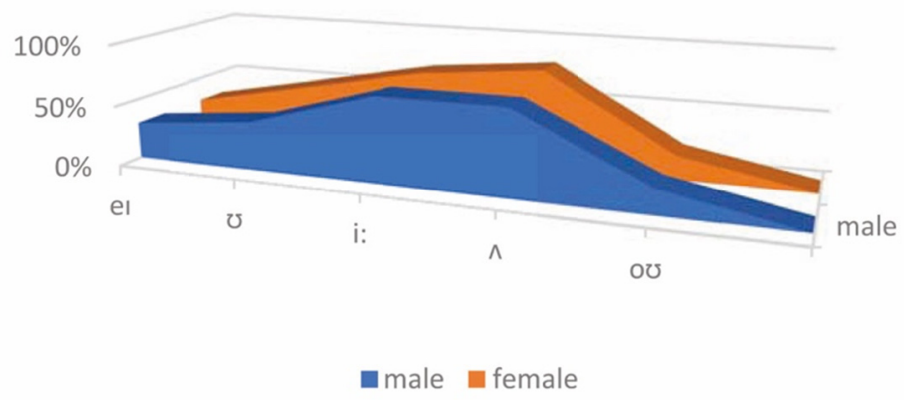

Chart 3. Realization percentages by gender

As shown in Chart 3, female participants are more correct in realizing the investigated vowels

From the study's focus group interviews the researchers found that, generally speaking, the informants perceived various words as the easiest to read. A thorough investigation of the factors that may have affected their choice showed that the factors mainly changed according to age group. For example, most participants of a younger age group claimed they perceived certain words as the easiest to read as a result of being shorter and/or more common than the rest in the lists. Moreover, 5/6 participants of the older age group claimed they perceived certain words to be the easiest to read based on the close orthography-pronunciation resemblance. The majority of the informants stated that they realize acoustic differences between how they produce a word and how a native speaker of English produces the same word. During the interview, the younger participants noted that they frequently associate a word with another word with a similar spelling (orthography) during their reading attempts. On the other hand, older participants seemed to use various strategies during their attempts in reading, including phonemic sounding, sound-spelling association, or a mixture of both. 


\section{Discussion}

Our main objective in this study is to find out the factors that seem to be at work when Kuwaiti learners of English pronounce five different vowels (three monophthongs including $[\Lambda],[\mathrm{I}],[\mathrm{\mho}]$, and two diphthongs [eI] and [ov] as they appear in actual English words. Three major second language error analyses factors (suggested by Steiberg \& Sciarini, 1993) were placed under the focus of our current research.

The first factor behind major second language errors was "interference", whereby in the process of word recognition, the speaker is able to recognize the English vowels, but replaces it with an L1 vowel as the improper pronunciation could be more likely due to a case of interference. Therefore, a Kuwaiti student who has had 12 years of exposure to English, and expectedly knows how the vowels of English should sound, might have replaced the English vowel with an existing vowel in the learner's mother tongue because of haste. The second factor behind L2 errors is second language strategy (L2 strategy), whereby the learner has, to some extent, learned the vowel system of the second language and its application in various words. Yet, mistakenly, the speaker thought that a certain vowel sequence should be pronounced in a certain way, or a case of uncertainty, that has resulted in a strategy of overgeneralization. The third factor affecting L2 errors is the first language strategy (L1 strategy). These errors occur as the learner does not know the rule yet. Therefore, s/he resides intentionally to his or her first language vowel system, and utilizes it to compensate for the lack of the knowledge of the new language.

These three second language learners' error analyses factors may lead to several realization tendencies. First, the speaker substitutes the English sounds that do not exist in the learners' mother tongue with one which does, due to the learner's unfamiliarity with the foreign sound. Another tendency is when the L2 speaker overgeneralizes the rules of English spelling due to inconsistent orthography-sound pattern of the vowel system in the English language. It has also been claimed that the learner of English usually encounters exceptional difficulties in reading loan words, due to their unique spelling that fails to resemble sounds represented by vocabulary items originally existing in the language. Within this scope, it's essential to mention that another principal reason why English orthography fails to resemble pronunciation is that English spelling has failed to reflect the drastic changes the spoken language has undergone throughout its history. Thus, the German sound $[\mathrm{x}]$, for example (used to exist in words like "light" and "right") has disappeared from the English phonology system, yet remained in its orthography system.

Data extracted from 64 recordings - as produced by the study's sample — were analyzed quantitatively using Praat, to enable us to compare participants' qualities of the vowels' production under the focus of this study, with average GA acoustic properties. At that point, our results indicated that the two investigated diphthongs [er] and [ov] tend to be the most challenging vowels to Kuwaiti speakers of English as reflected by the very low percentage of an overall correct realizations of the two vowels $(26 \%, 22 \%)$ consecutively. The data also showed that female participants seem to generally have a better realization of the two presented diphthongs when compared to the study's male counterparts. Nevertheless, such tendency has not reached the required statistical significance. The data also reflected that young participants have significantly outperformed their older counterparts in the production of [er]. Investigation of the incorrect representation of the diphthong shows that our participants have mainly resided to replace [eI] with an existing monophthong, namely GA [e]. Our search for an explanatory orthography-pronunciation relationship has further indicated no trace. When bearing in mind the existence of the diphthong in Kuwaiti's mother tongue, we could safely conclude that an L1 strategy or interference could be less likely at work. We, therefore, conclude that the pronunciation error could probably be the result of L2 strategy, whereby the learner tends to overgeneralize the production of GA [e] to replace [eI]. The low percentage of correct realization of the vowel (around $25 \%$ only) may also indicate that the problem is less likely evidence of L1 transfer. This is assumed since the differences found in the phonology system of the two languages, namely English and Kuwaiti in our case, might lead to differences in acoustic features of the learned language. Hence, how Kuwaitis perceive English sounds, would lead to the production of a foreign accent. The issue will be further tackled during our focus group interviews when it resurfaces.

The second investigated diphthong [ov] seemed to have been even more problematic than [er] among Kuwaiti speakers. Results of our study's investigation show that the diphthong [ov] was most frequently realized as [0], a vowel that exists in Kuwaitis' dialect vowel system. The finding suggests that participants tend to reside to their L1 vowel system to compensate for their inability to produce a sound that does not exist in their L1 phonetic system. A closer look into the variable performance of the participants has, once again, indicated a better performance amongst the younger group, with a significant proper pronunciation of $15 \%$ more than the older group. There was also a tendency of female participants outperforming their male counterparts. 
As for monophthongs, all three vowels were incorrectly realized based on orthography-sound patterns of the English words. $[\mho]$ and [i:] were interchangeably mispronounced with $[\mathrm{u}:]$ and $[\mathrm{I}]$, with some very prominent associations to English orthography-speech patterns. Despite the fact that the speakers' mother tongue includes an altered variation of the vowel $[\Lambda]$, namely [a], our findings suggest that Kuwaiti speakers realized the vowel in accordance to its orthographical profile in the word $(\mathrm{o} \rightarrow \mathfrak{x})$ as in (double), and $(\mathrm{u} \rightarrow \Lambda)$ as in (but). At one point, the short back vowel [v] has been replaced with the long back vowel [u:] around $50 \%$ of the time. Younger group participants have outperformed their older counterparts. Female participants have also significantly performed better than the male participants. Evidences associated words with the spelling of $\mathrm{CooC}$ to the long back vowel [u:] as it is in the case of "book", and CuC to the short back vowel [v] as illustrated in the case of "put". Such finding indicates that Kuwaiti learners tend to mispronounce the vowel $[\mho]$ as a result of L2 strategy; they seem to associate the vowel sound with its orthographical profile. This finding seems to support McCarthy's explanation for learner pronunciation difficulties on the grounds of the fact that Arabic vowel length is phonemic, while the English one is not (McCarthy, 2005).

To a lesser extent, the association of orthography to incorrect realization has also been detected in the case of [i:] and [I]. The two front vowels were interchangeably mispronounced based on the orthography of the word. For instance, "been" has frequently been pronounced as [bi:n], perhaps based on the fact that "feel" is pronounced as [fi:1]. "Ship", on the other hand, was more likely realized as [fi:p]. Moreover, words with the spelling of "CeaC", as it is in the case of "meat", has also been phonemically associated with words like "pear" and "bear", and therefore were incorrectly realized as [pi:r] and [bi:r]. Considering the fact that both front vowels (short and long) do exist in the mother tongue of Kuwaitis, this could be another evidence that relates the incorrect realization of the vowel to an incident of overgeneralization of the English spelling rules due to inconsistent orthography-sound pattern.

A further orthography-sound association has been viewed in the case of the back mid vowel $[\Lambda]$. With the exception of "touch" and "cousin" (perhaps due to being more common than the other items in the presented reading list), our results demonstrate more frequent incorrect realization of the vowel when presented orthographically by [ov], as it is in the case of "double". On the contrary, the same vowel was correctly realized whenever resembled by "u", as it is in the case of "but". Our data has successively shown a more correct realization of the vowel amongst the younger group of participants. A variation of the back mid vowel $[\Lambda]$ does exist in Kuwaitis' phonology system. Furthermore, it has been noticed through our observation that the vowel has been correctly realized when reflected orthographically with $[\mathrm{u}]$. Thus, one could logically claim that any incorrect realization of the vowel would more likely be due to an overgeneralization of the English orthography-sound system.

A comprehensive look into our quantitative findings suggest that, all in all, four out of the five investigated vowels, were significantly realized more correctly amongst our study's younger age group. There were also tendencies from female participants of showing more correct realizations of all five vowels than the male participants, with the exception of $[\mho]$, none of which has reached the required statistical levels. Most of Kuwaitis' incorrect realizations have shown to be related to orthography-sound pattern in the L2 (namely English in our case). The current study reveals some contradicting findings to the claims made by researchers in studies conducted on other Arab speaking communities (Sudanese). These studies mainly claim in their conclusion that mispronounced vowels are a cause of differences between L1 and L2 vowel realizations, and to a lesser extent, the lack of L2 (English) phonemic knowledge (Ali, 2013).

To get more insight into the issue under the focus of our study, our findings from the focus group interview results have additionally signaled a number of important issues. An essential finding was that almost all of the informants claim to have realized acoustic differences between their incorrect vowel realization and the correct ones. The finding suggests that it is less likely that the participants' incorrect vowel realizations could be related to L1 sound misconception. Once again, this emphasizes our previous justification for most of the mispronounced vowels as incidences of orthography-sound related patterns rather than any of the other previously mentioned factors.

Another finding is that, while younger Kuwaiti learners tend to base their realization of the vowels more frequently on orthography-sound pattern of the English language, older Kuwaitis tend to rely on another vowel realization strategy, i.e., phonemic sounding. This, in fact, may explain why younger Kuwaitis were able to outperform older Kuwaitis in almost all five vowels. The nature of the word lists to which the study's sample was exposed to has also led to a number of inconsistent results. Our qualitative data show that most of the younger group participants found few words easier than others due to the intrinsic nature of the word rather than its orthography and/or the vowel under investigation. 


\section{Conclusion}

In an attempt to analyze the difficulties Kuwaiti learners of English encounter in the realization of five major vowels of English, our current research has mainly suggested three main reasons behind L2 vowel error. The first reason is L1 transfer, when the learner has learned the rule of the vowel production, but mistakenly resides to L1 vowel production, perhaps as a result of haste. Overgeneralization of an L2 vowel sound-orthography pattern is a second cause of error. The final reason was labeled L2 strategy, when the learners' mother tongue lacks certain vowels, it leads to L1 habits of speaking that are different in perception, such as, use of speaking organs and suprasegmental features (Carter \& Nunan, 2001).

Our findings indicate that Kuwaiti learners face difficulties in the realization of all five vowels. Kuwaiti learners, especially young learners, tend to mainly overgeneralize orthography-sound patterns of English phonology rules. Even when the vowel does not exist in the phonology system of their mother tongue, rather than residing to their own phonology system, young Kuwaiti learners tend to associate vowel pronunciation to words with similar orthographical profile. Older Kuwaiti learners on the other hand, tend to utilize literal sound-letter pronunciation, alongside orthography-sound patterns in their attempts. This strategy might have led to more incorrect realizations of the English vowels among the older Kuwaiti learners than their younger counterparts. With that said, our findings suggest an extremely dark profile of Kuwaiti speakers of English across various age groups. The Kuwaiti speakers are expected to use unintelligible English, due to the significant role of pronunciation on the speakers' speech intelligibility regardless of the grammatical errors it contains (Gilakjani, 2012). Future research on the topic could follow up by selecting unified word lists, in terms of their length and familiarity, so as to control any confounding factors that may play a role in the participants' sound realization ability. We also advocate future researchers of the topic to account for the effect of the learners' competency level in English on the variability of English vowel realizations, a factor that has not been accounted for in the present study.

To conclude, our findings and analyses indicate that Kuwaiti speakers find all five investigated vowels challenging, with the two diphthongs to be the most difficult to realize. Regardless of their existence in their mother tongue, Kuwaiti speakers tend to shorten the diphthong vowel and change it into its closest corresponding monophthong (er>e; ou> o). No orthography-sound pattern was detected in the two diphthong incorrect realizations. To a lesser extent, Kuwaiti speakers encounter difficulties in the realization of the

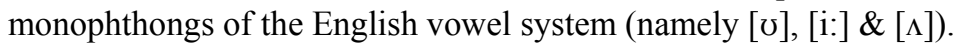

The present study's conclusions should be taken into consideration when teaching English to young learners. Our findings highlight the importance of associating the teaching of English phonemes, especially vowels, with various existing orthography-sound patterns in the language. According to our findings, we believe the implementation of this methodology in teaching English might enhance the learners' realizations of English sounds as they appear in actual words. We therefore claim that educators and curriculum designers should shift their focus, which is currently only emphasizing the teaching of grammar, vocabulary and morphology into one that gives the production of intelligible pronunciation an equal importance in the future syllabi of English teaching in the schools of Kuwait. A very beneficial way of implementing such crucial shift might be in establishing the importance of language labs alongside language lessons. It is also important to reinforce the significance of providing newly established schools and other educational institutions with an appropriate infrastructure for the recommended shift.

\section{References}

Ahmad, W. A. S. W. (2005). Vowel length discrimination among Malay speakers of Malaysian English: An instrumental study (Doctoral dissertation, Fakulti Bahasa dan Linguistik, Universiti Malaya).

Ali, E. M. T. (2013). Pronunciation problems: Acoustic analysis of the English vowels produced by Sudanese learners of English. International Journal of English and Literature, 4(10), 495-507.

Alimemaj, Z. M. (2014). English phonological problems encountered by Albanian learners. European Scientific Journal, 10(8).

Alotaibi, Y. A., \& Hussain, A. (2010). Comparative analysis of Arabic vowels using formants and an automatic speech recognition system. International Journal of Signal Processing, Image Processing and Pattern Recognition, 3(2), 11-22.

Al-Saidat, E. M. (2010). Phonological analysis of English phonotactics: A case study of Arab learners of English. The Buckingham Journal of Language and Linguistics, 3, 121-134.

Al-Samawi, A. M. (2014). Vowelizing English consonant clusters with Arabic vowel points (Harakaat): Does it help Arab learners to improve their pronunciation. International Journal of English and Education, 3(3), 
263-282.

Atkinson, R., \& Flint, J. (2001). Accessing hidden and hard to reach population: Snowball research strategies. Social Research Update, Issue 33. Guildford (England): University of Surrey, Department of Sociology.

Brown, H. D. (2000). Principles of Language Learning and Teaching (4th ed.). Longman: Sanfrancisco State University.

Carter, R., \& Nunan, D. (2001). The Cambridge Guide to Teaching English to Speakers of Other Languages. Cambridge: Cambridge University Press. http://dx.doi.org/10.1017/CBO9780511667206

Delattre, P. (1964). Comparing the vocalic features of English, German, Spanish and French. IRAL, 2(2), 71-97. https://doi.org/10.1515/iral.1964.2.1.71

Flege, J. E. (1987). The instrumental study of L2 speech production: Some methodological considerations. Language Learning, 37(2), 285-296. https://doi.org/10.1111/j.1467-1770.1987.tb00569.x

Flege, J. E. (1987). The production of "new" and "similar" phones in a foreign language: Evidence for the effect of equivelence classification. Journal of Phonetics, 15, 47-65.

Flege, J. E. (1995). Second language speech learning: Theory, findings, and problems. In W. Strange (Ed.), Speech Perception and Linguistic Experience: Issues in Cross-language Research (pp. 233-277). Timonium, MD: York Press, Inc. https://doi.org/10.1177/002383099503800102

Flege, J. E. (1996). English vowel production by Dutch talkers: More evidence for the "similar" vs "new" distinction. In A. James \& J. Leather (Eds.), Second Language Speech: Structure and Process (Vol. 13, pp. 11-52). Berlin: Walter de Gruyter \& Co.

Gilakjani, A. P. (2012). The significance of pronunciation in English language teaching. English Language Teaching, 5(4), 96.

Gimson, A. C., \& Crutteden, A. (1994). Gimson's Pronunciation of English. London: Edward Arnold.

Homidan, A. H. (1984). Utilizing the Theory of Articulatory Settings in the Teaching of English Pronunciation to Saudi Students Learning English as a Second Language. Doctoral Dissertation, King Fahd Public Library.

Jabbari, A. A., \& Samavarchi, L. (2011). Persian learners' syllabification of English consonant clusters. International Journal of English Linguistics, 1(1), 236-246. https://doi.org/10.5539/ijel.v1n1p236

Kivistö-de Souza, H., \& Carlet, A. (2016). Vowel Inventory Size and the Use of Temporal Cues in Non-Native Vowel Perception by Catalan and Danish EFL Learners. In Proceedings of the International Symposium on the Acquisition of Second Language Speech Concordia Working Papers. Applied Linguistics, 5, 322-336.

Kopczynski, A., \& Meliani, R. (1993). The vowels of Arabic and English. Papers and Studies in Contrastive Linguistics, 27, 183-192.

Kwon, H. (2007). A Phonetic Analysis of Korean EFL Learners' Production of English Reduced Vowel. NU Working Papers. English Linguistics and Language, 6, 1-13.

Lenneberg, E. H. (1967). Biological Foundations of Language. New York: Wiley.

McCarthy, J. J. (2005). The length of stem-final vowels in Colloquial Arabic. Perspectives on Arabic linguistics XVII-XVIII, 1-26. https://doi.org/10.1075/cilt.267.03mcc

Newman, D., \& Verhoeven, J. (2002). Frequency analysis of Arabic vowels in connected speech. Antwerp Papers in Linguistics, 100, 77-86. https://doi.org/10.1179/2050572813Y.0000000012

O’Connor, J. D. (1980). Better English Pronunciation (2nd ed.). Cambridge: Cambridge University Press.

Paunović, T. (2017). Sounds Serbian? Acoustic properties of Serbian EFL students' speech. Selected Papers on Theoretical and Applied Linguistics, 19, 357-369.

Roach, P. (2000). English phonetics and phonology (3rd ed.). Cambridge: Cambridge University Press.

Salem, S. T. (2014). The modification of English/s/+ consonant onset clusters by Levant Arabic speakers. University of Lethbridge (Canada).

Tsukada, K. (2009). An acoustic comparison of vowel length contrasts in Arabic, Japanese and Thai: Durational and spectral data. Int. J. of Asian Lang. Proc., 19(4), 127-138.

Tsukada, K. (2013). Vowel length categorization in Arabic and Japanese: Comparison of native and non-native Japanese perception. Speech, Language and Hearing, 187-196. 
https://doi.org/10.1179/2050572813Y.0000000012

Wang, S. H., \& Wu, J. C. (2001). The effect of vowel duration on the perception of postvocalic voiced/voiceless consonants. Concentric: Studies in Linguistics, 27(2), 35-52.

Yiing, I. K. C. (2011). An analysis of pronunciation errors in English of six UTAR Chinese studies undergraduates. Faculty of arts and social science (Universiti Tunku Abdul Rahman).

Yule, G. (1996). The Study of Language (2nd ed.). Cambridge: Cambridge University Press.

Zhang, A., Feng, H., Dang, J., Zheng, X., \& Xu, Z. (2015). The Perception of English Vowel Contrasts by Chinese EFL Learners and Native English Speakers. In The Scottish Consortium for ICPhS 2015 (Ed.), Proceedings of the 18th International Congress of Phonetic Sciences. Glasgow, UK: the University of Glasgow. $\quad$ Retrieved from http://www.internationalphoneticassociation.org/icphs-proceedings/ICPhS2015/Papers/ICPHS1041.pdf

\section{Copyrights}

Copyright for this article is retained by the author(s), with first publication rights granted to the journal.

This is an open-access article distributed under the terms and conditions of the Creative Commons Attribution license (http://creativecommons.org/licenses/by/4.0/). 